\title{
HOUSEHOLD PRODUCTION AND THE EXCESS SENSITIVITY OF CONSUMPTION TO CURRENT INCOME
}

\author{
Marianne Baxter
}

Urban J. Jermann

Working Paper 7046

http://www.nber.org/papers/w7046

\section{NATIONAL BUREAU OF ECONOMIC RESEARCH \\ 1050 Massachusetts Avenue \\ Cambridge, MA 02138 \\ March 1999}

This project has benefited from the comments of Robert G. King, Matthew D. Shapiro, and an anonymous referee, as well as seminar participants at Dartmouth College, Harvard University, University of Michigan, University of Texas-Austin, University of Virginia, the Wharton School, and the NBER Meeting on "Micro and Macro Foundations of the Aggregate Labor Market." Any remaining errors are our own. Baxter gratefully acknowledges the support of the National Science Foundation. Any views expressed in this paper are those of the author only and not those of Columbia University or the National Bureau of Economic Research.

(3) 1999 by Marianne Baxter and Urban J. Jermann. All rights reserved. Short sections of text, not to exceed two paragraphs, may be quoted without explicit permission provided that full credit, including ${ }^{\mathbb{C}}$ notice, is given to the source. 
Household Production and the Excess

Sensitivity of Consumption to Current Income

Marianne Baxter and Urban J. Jermann

NBER Working Paper No. 7046

March 1999

JEL No. D13, E10, E21

\section{ABSTRACT}

Empirical research on the permanent income hypothesis (PIH) has found that consumption growth is excessively sensitive to predictable changes in income. This finding is interpreted as strong evidence against the PIH. We propose an explanation for apparent excess sensitivity that is based on a quantitative equilibrium version of Becker's (1965) model of household production in which permanent income consumers respond to shifts in sectoral wages and prices by substituting work effort and consumption across home and market sectors. Although the PIH is true, this mechanism generates apparent excess sensitivity because market consumption responds to predictable income growth.

Marianne Baxter

Department of Economics

Rouss Hall 116

University of Virginia

Charlottesville, VA 22901

and NBER

mb6s@virginia.edu
Urban J. Jermann

Finance Department

The Wharton School

University of Pennsylvania

3620 Locust Walk

Philadelphia, PA 19104

and NBER

jermann@wharton.upenn.edu 
The permanent-income/life-cycle hypothesis (PIH) has come to occupy a central position in mainstream macroeconomics since its inception nearly forty years ago in the writings of Milton Friedman (1957). Although the PIH is taken as axiomatic in many macroeconomic investigations, the question of its empirical accuracy continues to form the basis for an active empirical literature which we survey in section I below. Many of these studies find that consumption growth rates are robustly correlated with predictable changes in real income. This finding is sometimes described as the "excess sensitivity" of consumption to income and is interpreted as strong evidence against the PIH.

This paper proposes an explanation for apparent excess sensitivity that is consistent with the PIH. Our starting point is Gary S. Becker's (1965) model of a household in which individuals substitute between home and market produced consumption goods according to their relative price. We will show that a model incorporating production and consumption of home-produced goods provides a compelling rationale for the observed empirical relationship between consumption and output.

The link between household production and the business cycle has been the subject of several recent papers. ${ }^{1}$ These papers find that interactions between the 
household and market sectors in a quantitative general equilibrium model improve the model's predictions concerning the central business cycle facts relative to a prototypical one-sector real business cycle model. These household production models do not test the PIH: they embed permanent income theory as part of the structure of the model. However, the model turns out to have striking predictions for the empirical findings that a researcher would obtain if he investigated excess sensitivity using data on market consumption and market output alone.

The basic idea behind household production in a theory of the business cycle is that individuals substitute between home and market goods depending on the wage rate. That is: the market wage rate measures the opportunity cost of engaging in household production, so an increase in the market wage during an economic expansion should be accompanied by an increase in market work and purchases of market goods and a corresponding decrease in household production. Examples of goods for which there are especially good possibilities for substitution between market purchase versus home production include the following: child care; home maintenance (housecleaning, lawn mowing, painting, repairs, and the like); food preparation; financial services such as preparation of income tax returns; and clothing (sewing and repair).

Since the household production model predicts that income growth and growth 
in the opportunity cost of home-produced goods are highly correlated, there is a natural reason for a positive correlation between market consumption growth and predictable changes in income. Using a quantitative equilibrium business cycle model with household production, we show that the empirical finding of excess sensitivity of market consumption to market income emerges even though individuals have rational expectations and act as permanent income consumers when consumption is appropriately defined to include goods produced at home. Essentially, the standard "excess sensitivity" regression is misspecified because it focuses on market consumption and market income, when it should properly be specified as a relationship between aggregate consumption and aggregate income. ${ }^{2}$

The paper is structured as follows. Section I reviews the empirical literature on the excess sensitivity of consumption. Section II develops a partial equilibrium model of consumer choice that illustrates how apparent excess sensitivity arises naturally in the presence of a nonmarket consumption good. The partial equilibrium nature of the model allows us to develop intuitive, closed-form solutions for the relationship between consumption growth and predictable income growth. Section III closes the model of section II by specifying the production side of the economy and determining prices and interest rates endogenously. The section ends with a brief description of the business cycle implications of the model. Section 
IV studies the implications of the general equilibrium model for the coefficients in a regression of market consumption growth on the predictable component of income growth and on the interest rate. We consider several plausible specifications for the productivity process which drives the model. Further, we explore the sensitivity of the parameter estimates to alterations in the specification of the consumption regression and explore the extent to which small sample bias may be important. Overall, we find a robust prediction of "excess sensitivity" in the sense that expected income growth in the market sector predicts growth in market consumption. Section V concludes.

\section{Related literature}

In his seminal paper, Robert E. Hall (1978) showed that consumption should follow a random walk in a simple intertemporal equilibrium model with a constant interest rate. He finds that lagged income is not significant for consumption growth, and he thus concludes in favor of the permanent income hypothesis. Subsequently, however, Marjorie Flavin (1981) found that consumption is excessively sensitive to income in the sense that current income still has explanatory power after accounting for the innovation in permanent income. Most recently, John Y. Campbell and N. Gregory Mankiw $(1989,1990,1991)$ used instrumental variable 
techniques to estimate the coefficient on predictable changes in income in consumption growth regressions and argued that this coefficient measures the fraction of consumption attributable to individuals who, as a rule of thumb, consume their current income.

In addition to the rule-of-thumb consumption function, several possible explanations for the empirical failure of Hall's basic model have been suggested. Most of these consider the relaxation of the simplifying assumptions of the initial model. The following representation of the consumer's first order condition, which is somewhat more general than Hall's, suggests various avenues for reconciling the empirical evidence with modern versions of the permanent income hypothesis:

$$
u^{\prime}\left(C_{t}, X_{t}\right)=\beta E_{t}\left[u^{\prime}\left(C_{t+1}, X_{t+1}\right)\left(1+r_{t, t+1}\right)\right]
$$

In the expression above, $u^{\prime}\left(C_{t}, X_{t}\right)$ is momentary marginal utility which depends on consumption of nondurables and services, $C_{t}$, and on other factors $X_{t}$ which affect the marginal utility of consumption, and $r_{t, t+1}$ denotes the interest rate between periods $t$ and $t+1$. Thus one possible explanation for the failure of Hall's basic model is a variable interest rate. Campbell and Mankiw consider whether the interest rate explains excess sensitivity. They find, however, that empiri- 
cally the interest rate does not explain much of consumption growth. Another proposed explanation for excess sensitivity is time-varying precautionary saving behavior, related to a time-varying conditional variance of consumption. This line of argument has been pursued by Ricardo J. Caballero (1990). Finally, Lawrence Christiano et al. (1991) explore the role of temporal aggregation in generating spurious excess sensitivity.

Another proposed reconciliation of the PIH with apparent excess sensitivity is based on other factors which enter nonseparably in the marginal utility function, as represented above by the variable $X_{t}$. The most obvious are nonseparabilities related to different classes of consumption goods (e.g., consumer durables vs. consumer non-durables, or consumption vs. leisure), or nonseparabilities over time due to habit formation. If movements in $X_{t+1}$ are predictable and if they are related to predictable changes in income, the nonseparability can generate the excess sensitivity result. John Cochrane (1991) suggests this as one potential interpretation of the Campbell-Mankiw results. Empirical evidence on the hypothesis that excess sensitivity is due to nonseparability of consumer durables from nondurables is inconclusive: Campbell and Mankiw (1990) and Mankiw (1985) do not reject separability, while Martin Eichenbaum and Lars Hansen (1990) find some evidence against separability between durables and nondurables. 
Our proposed explanation for apparent excess sensitivity hinges on a particular nonseparability: that between market goods and home goods in momentary utility. While substitutions between consumption and leisure are also part of our story, it is more plausible that the most important channel involves substitution across alternative methods for producing final consumption goods. Further, in addition to substitution across consumption goods, individuals in our model also substitute between productive activities depending on the relative rewards to work in each sector. The combination of these two effects provides an explanation for the empirical finding of excess sensitivity.

\section{A simple model}

This section develops a partial equilibrium model of consumer choice that illustrates how apparent excess sensitivity arises in the presence of a nonmarket consumption good. Specifically, we show that the growth of market consumption is positively related to the predictable component of labor income growth.

The representative individual derives utility from market consumption, $C$, from home-produced consumption, $H$, and from leisure, $L$, and maximizes ex- 
pected lifetime utility given by:

$$
E_{0} \sum_{t=0}^{\infty} \beta^{t}\left(\frac{1}{1-\sigma}\right) \varphi\left(C_{t}, H_{t}\right)^{1-\sigma} v\left(L_{t}\right)
$$

where $\varphi($.$) is a linearly homogeneous aggregator of the two consumption goods;$ $v\left(L_{t}\right)$ measures the utility derived from leisure; $\sigma$ is the coefficient of relative risk aversion; and $\beta$ is the subjective discount factor. The individual's time constraint takes the form:

$$
T=N_{H t}+N_{M t}+L_{t}
$$

where $T$ is the amount of nonsleeping time available for working or consuming leisure; $N_{H t}$ is the amount of time that individuals allocate to the production of the home-produced good; $N_{M t}$ is time devoted to market work; and $L_{t}$ denotes time spent in leisure activities. We follow the literature in assuming that an hour devoted to market work generates the same disutility as an hour of nonmarket work.

The representative individual's assets evolve according to the following:

$$
Z_{t+1}=\left(1+r_{t, t+1}\right)\left(Z_{t}+W_{t}\left(T-N_{H t}-L_{t}\right)-C_{t}\right)
$$


where $Z_{t+1}$ denotes individual asset holdings at the beginning of period $t+1$ and $W_{t}$ is the wage rate in the market sector. We have assumed, for simplicity, that the representative agent holds a single asset (which may be a portfolio) that earns the exogenous real return $r_{t, t+1}$ between periods $t$ and $t+1$.

Household production is assumed to require labor alone, according to a linear technology (this assumption will be relaxed in the general equilibrium model of the next section). Letting $A_{H t}$ denote the (possibly stochastic) level of labor productivity in the home sector, consumption of the home good, $H_{t}$, is constrained by:

$$
A_{H t} N_{H t}=H_{t}
$$

In equilibrium, the following three conditions must hold, where $\varphi_{j}\left(C_{t}, H_{t}\right)$, $\nu_{j}\left(L_{t}\right)$ denote the partial derivatives of $\varphi$ and $\nu$ at date $t$ with respect to variable $j:$

$$
\varphi\left(C_{t}, H_{t}\right)^{-\sigma} v\left(L_{t}\right) \varphi_{C}\left(C_{t}, H_{t}\right)=\beta E_{t}\left[\varphi\left(C_{t+1}, H_{t+1}\right)^{-\sigma} v\left(L_{t+1}\right) \varphi_{C}\left(C_{t+1}, H_{t+1}\right)\left(1+r_{t, t+1}\right)\right]
$$




$$
\begin{gathered}
\frac{\varphi_{H}\left(C_{t}, H_{t}\right)}{\varphi_{C}\left(C_{t}, H_{t}\right)}=\frac{W_{t}}{A_{H t}} \\
\frac{\varphi\left(C_{t}, H_{t}\right)^{1-\sigma} v_{L}\left(L_{t}\right)}{(1-\sigma) \varphi\left(C_{t}, H_{t}\right)^{-\sigma} v\left(L_{t}\right) \varphi_{C}\left(C_{t}, H_{t}\right)}=W_{t} .
\end{gathered}
$$

Equation (0.6) is the intertemporal efficiency condition relating the marginal utility in period $t$ to discounted marginal utility in period $t+1$, while equations $(0.7)$ and $(0.8)$ are intratemporal efficiency conditions relating relative prices and marginal utilities.

We can obtain a closed form solution for this model by taking a log-linear approximation to the Euler equations. To simplify, we let productivity be constant in the household sector: $A_{H t}=A_{H}$. Log-linear approximation of (0.6) yields the following relationship between expected growth of consumption and expected wage growth, where lowercase letters denote percentage deviations from the point of linearization (except for $r_{t, t+1}$, defined earlier as the risk-free interest rate):

$$
E_{t}\left(\Delta c_{t+1}\right)=\alpha_{1} E_{t}\left(\Delta w_{t+1}\right)+\alpha_{2} E_{t} r_{t, t+1} .
$$

with 


$$
\begin{gathered}
\alpha_{1}=\frac{\xi_{\varphi l}-\left(1-s_{c}\right) \xi_{l l}}{\sigma \xi_{l l}+(1-\sigma) \xi_{\varphi l}}+\left(1-s_{c}\right) \zeta \\
\alpha_{2}=\frac{\xi_{l l}-\xi_{\varphi l}}{\sigma \xi_{l l}+(1-\sigma) \xi_{\varphi l}} .
\end{gathered}
$$

In the expressions above, $s_{c}$ denotes the share of market consumption in the consumption aggregate $\varphi ; \zeta$ denotes the elasticity of substitution between market consumption and consumption of goods produced at home; $\xi_{\varphi l}$ is the elasticity of the marginal utility of the consumption aggregate with respect to leisure $\xi_{l l}$ denotes the own-elasticity of the marginal utility of leisure.

To gain insight into the relationship between consumption growth and wage growth, it is instructive to study two special cases of equation (0.9). First, suppose there is no household good, so that $s_{c}=1$. Then the expression for $\alpha_{1}$ simplifies to

$$
\alpha_{1}=\frac{\xi_{\varphi l}}{\sigma \xi_{l l}+(1-\sigma) \xi_{\varphi l}}
$$

The denominator of $(0.10)$ is negative by concavity of momentary utility. The numerator $\xi_{\varphi l} \gtrless 0$ if $\sigma \lessgtr 1$, so the condition for $\alpha_{1}>0$ in the case with no household production is $\sigma>1$ : the marginal utility of consumption falls with 
increases in leisure.

A second special case involves zero elasticity of substitution between the home and market good: $\zeta=0$. In this case, $\alpha_{1}$ becomes

$$
\alpha_{1}=\frac{\xi_{\varphi l}-\left(1-s_{c}\right) \xi_{l l}}{\sigma \xi_{l l}+(1-\sigma) \xi_{\varphi l}}
$$

Compared with the no-household-production case, this expression for $\alpha_{1}$ has a new term in the numerator, $-\left(1-s_{c}\right) \xi_{l l}$, which reflects a "price effect" of an increase in the market wage on consumption. When the market wage rises, the consumption aggregate $\varphi$ becomes more expensive because time is needed to produce the home good. This price effect, taken by itself, would tend to reduce consumption of the composite good. Thus introducing household production in a way that permits no substitutability between home and market goods would tend to reduce the responsiveness of market consumption to changes in the wage rate.

When individuals are willing to substitute between home and market goods, $\zeta>0$, then the final term appears in the expression for $\alpha_{1}:\left(1-s_{c}\right) \zeta$. This term reflects the effect on market consumption of substitutions between home and market goods when their relative price changes. As noted above, an increase in the market wage increases the price of home goods relative to market goods. 
Individuals will then shift consumption toward market goods-the extent to which they are willing to do this depends on the elasticity of substitution $\zeta$.

Thus, we find that $\alpha_{1}$ is likely to be positive, even if there is no home production, simply because of substitution between consumption and leisure. The price effect of home production tends to reduce the value of $\alpha_{1}$, while increases in the substitutability between home and market goods will increase $\alpha_{1}$. A sufficient condition for $\alpha_{1}>0$ is $\sigma>1, \zeta \geq 1$. As we discuss more fully in the next section, these parameter restrictions appear to be satisfied in the data.

How does effort devoted to market work vary with the market wage and the interest rate? Working again with the log-linear approximation to the model, we obtain the following expression for the growth rate of market labor input:

$$
E_{t}\left(\triangle n_{M, t+1}\right)=\gamma_{1} E_{t}\left(\triangle w_{t+1}\right)+\gamma_{2} E_{t} r_{t, t+1}
$$

where

$$
\begin{gathered}
\gamma_{1}=\frac{\frac{N_{H}}{N_{M}}\left(\xi_{l l}\left(s_{c} \sigma \zeta+\left(1-s_{c}\right)\right)+\xi_{\varphi l}\left(s_{c}(1-\sigma) \zeta-1\right)\right)-\frac{L}{N_{M}}\left(1-s_{c}(1-\sigma)\right)}{\sigma \xi_{l l}+(1-\sigma) \xi_{\varphi l}} \\
\gamma_{2}=\frac{\frac{L}{N_{M}}-\frac{N_{H}}{N_{M}}\left(\xi_{l l}-\xi_{\varphi l}\right)}{\sigma \xi_{l l}+(1-\sigma) \xi_{\varphi l}} .
\end{gathered}
$$


Whether labor input is expected to rise or fall with increases in the wage rate depends on the sign of $\gamma_{1}$. Since $\gamma_{1}$ is the related to the compensated labor supply elasticity, it is likely to be positive. Further, we find that $\gamma_{1}$ is positive when parameters are set in accordance with estimates obtained by others in the context of household production models, as we shall show below.

Putting these pieces together, expected income growth is given by

$$
E_{t}\left(\triangle y_{t+1}\right)=E_{t}\left(\triangle n_{M, t+1}\right)+E_{t}\left(\triangle w_{t+1}\right)
$$

Using equations (0.9) and (0.11) above, we find that expected consumption growth is related to expected income growth by the following:

$$
E_{t}\left(\triangle c_{t+1}\right)=\frac{\alpha_{1}}{1+\gamma_{1}} E_{t}\left(\triangle y_{t+1}\right)+\frac{\alpha_{2}\left(1+\gamma_{1}\right)-\gamma_{2}}{1+\gamma_{1}} E_{t} r_{t, t+1}
$$

Thus we have that expected growth of market output is positively correlated with the growth of market consumption if $\alpha_{1}>0$ and $\left(1+\gamma_{1}\right)>0$, as seems likely in light of our prior discussion. ${ }^{3}$ The economic mechanism behind this result is made transparent by the simplicity of the model. When future market wages are expected to be high, individuals plan to substitute labor input away from the home good and toward production of the market good. At the same time, they 
plan to substitute consumption of the market good for consumption of the home good (which they must since, holding $A_{H t}$ constant, there will be relatively less of the home good available if labor supply to the household sector declines). Thus there is a natural mechanism linking predictable income growth to the growth of market consumption. ${ }^{4}$

Finally, note that the coefficient on the interest rate is not equal to $1 / \sigma=1$ unless $\sigma=\zeta=1$. Thus this equation cannot, in general, be used to estimate $\sigma$ as the inverse of the coefficient on the interest rate. To estimate $\sigma$ in the context of this model, it is necessary to have data on household sector activity that would permit estimation of the shares and elasticities embedded in the coefficients in equation (0.13).

\section{A general equilibrium model}

This section closes the partial equilibrium model of section II by specifying the production side of the market economy, allowing both capital and labor to be used in the household sector, and determining prices and interest rates endogenously.

While a growing literature has shown that household production considerations may be important for understanding macroeconomic phenomena at business cycle frequencies, our concern is how household production alters the interpretation of 
standard tests of the permanent income hypothesis. Specifically, does the presence of the nonmarket sector rationalize the fact that consumption growth is related to predictable income growth? We find that the answer is "yes." Central to our story is the idea that individuals substitute labor supply across the market and nonmarket sectors depending on the relative opportunities available. At the same time, consumers value consumption of both the market-produced good and the non-market good (the home good), and substitute between these goods with variations in their relative price. The basic intuition developed in the partial equilibrium model of last section will carry over to this general equilibrium model. That is: when productivity is expected to be high in the market sector individuals will choose to increase labor supply to that sector. At the same time, the relative price of market goods will decline, so that expected consumption of the market good will rise. Thus expected growth of market output will be able to predict the growth of market consumption even though individuals act as rational, permanent income consumers.

\section{A. The model}

As in the partial equilibrium model of section II, the representative individual values consumption of the market-produced good, $C_{t}$, the home-produced good, 
$H_{t}$, as well as leisure, $L_{t}$. Individuals maximize expected lifetime utility, given by equation (0.2) above, subject to their time constraint, equation (0.3).

Production of the market good is governed by the following constant-returnsto-scale technology:

$$
Y_{M t}=A_{M t} K_{M t}^{\alpha}\left(X_{t} N_{M t}\right)^{1-\alpha}
$$

while production of the nonmarket good follows

$$
Y_{H t}=A_{H t} K_{H t}^{\imath}\left(X_{t} N_{H t}\right)^{1-\vartheta}
$$

$X_{t}$ is the deterministic trend in labor-augmenting technical change, common across sectors, which grows at the rate $\gamma=X_{t+1} / X_{t}$. The variables $A_{M t}$ and $A_{H t}$ are the stochastic components of technical change, which may contain unit roots.

In each sector, capital is subject to convex costs of adjustment, so that investment in each sector, $I_{M t}$ and $I_{H t}$ is translated into installed capital according to:

$$
K_{M, t+1}=\left(1-\delta_{M}\right) K_{M t}+\phi\left(I_{M t} / K_{M t}\right) K_{M t}
$$




$$
K_{H, t+1}=\left(1-\delta_{H}\right) K_{H t}+\phi\left(I_{H t} / K_{H t}\right) K_{H t}
$$

with $\phi^{\prime}>0, \phi^{\prime \prime}<0$.

The government of this economy purchases the market good in the amount $G_{t}$, taxes the returns to market work and market capital at the constant rates $\tau_{N}$ and $\tau_{K}$, and rebates any potential surplus proceeds to consumers as lump-sum transfers, $T R_{t}$. Government purchases neither yield utility to private individuals nor enhance the productivity of private factors of production. The government's budget constraint, expressed in units of the market good, is given by:

$$
\tau_{N} W_{t} N_{M t}+\tau_{K}\left(r_{K t}-\delta_{M}\right) K_{M t} \geq G_{t}+T R_{t}
$$

where $W_{t}$ is the market wage rate, and $r_{K t}$ is the rental rate of market capital.

Output of the nonmarket good is used solely for consumption, thus the associated resource constraint is simply

$$
Y_{H t} \geq H_{t}
$$

Output of the market good is used for private consumption, for government con- 
sumption, and for investment in each of the two sectors:

$$
Y_{M t} \geq C_{t}+G_{t}+I_{M t}+I_{H t}
$$

The competitive equilibrium for this economy is found using the log-linear method of King, Plosser, and Rebelo (1987).

\section{B. Calibration}

We have calibrated our model to conform as closely as possible with the recent literature on household production as summarized in the survey by Jeremy Greenwood et al. (1995). Our procedure is similar to theirs, in that we solve for the deterministic steady state of the model and calibrate the model's steady state by setting the following quantities to match corresponding averages in U.S. time series: the capital-output ratio in the market sector; the ratio of household capital to market capital; the shares of investment in the two sectors as a fraction of market output; time allocated to each of the two sectors and to leisure; tax rates; the trend rate of growth of total factor productivity; and the real interest rate. These parameters jointly determine the steady state, and thus implicitly

define the following parameters: the growth-adjusted subjective discount factor; 
the depreciation rates in the two sectors; labor's share in each sector; capital's share in each sector; and the share of market goods in aggregate consumption. The following parameters have no effect on the steady state; rather, they affect the model's dynamics: the elasticity of substitution between market and home goods; risk aversion; the own-elasticity of leisure; the elasticity of the adjustment cost function; and the parameters of the productivity shock process. Our baseline parameterization of the economy is as follows.

\section{Preferences}

The time period is a quarter of a year. The growth-adjusted subjective time discount factor is set so that the steady state real interest rate is $6.5 \%$ per year. The share of market goods in the consumption aggregate $\varphi$ is $s_{c}=0.63$. The amount of available nonsleeping time is normalized to 1 , of which $N_{M}=0.33$ is spent in market work including commuting, $N_{H}=0.25$ is spent in household production, and $L=0.42$ is consumed directly as leisure. These shares are from the 1971-1981 Michigan time surveys, and are averages over both men and women. The own-elasticity of leisure is set at $\xi_{l l}=-1$ in the baseline case. The coefficient of relative risk aversion is $\sigma=2$.

The elasticity of substitution between market and home goods, $\zeta$, plays an 
important role in our analysis. Until recently there has been little research which attempts to determine the appropriate value of this parameter. In the two early quantitative models with household production, researchers established a "preferred value" that was chosen to insure that the model performed well in terms of some key business-cycle facts. Specifically, Greenwood et al. (1995) chose $\zeta=3$, while Jess Benhabib et al. (1991) report a preferred value of $\zeta=5$. Subsequently, Ellen McGrattan et al. (1997) constructed a household production model similar to ours and used maximum likelihood to obtain an estimate of $\zeta$ using macroeconomic time series data. Their point estimate was 1.75 with a $95 \%$ confidence interval of $(1.25,2.95)$.

In another study, Peter Rupert et al. (1995) used micro data from the PSID to estimate $\zeta$ for three groups of consumers: single males; single females; and couples. The point estimate for single males was $\widehat{\zeta}=0.94$ (the $95 \%$ confidence interval is $(0.05,1.82)$. For single females, they report $\widehat{\zeta}=1.80$ with $95 \%$ confidence interval $(1.37,2.24)$. For couples, the estimate ranges from $\widehat{\zeta}=1.09$ (95\% confidence interval is $(0.45,1.73))$ to $\widehat{\zeta}=4.00$ (95\% confidence interval is $(3.02,4.98))$. The estimate depended on whether specific cross-equation restrictions were imposed during estimation. Based on this group of studies, a plausible range for $\zeta$ seems to be $\zeta \in(0.00,5.00)$. Our benchmark value is $\zeta=3$, but we also report results 
for other plausible values of $\zeta$.

\section{Technology}

The parameters of the two production technologies were set to match the following steady state values. First, the capital-to-output ratio in the market sector is equal to 4 , based on a concept of market capital that comprises producer durables and nonresidential structures. The ratio of household capital to market capital is set at 0.625 ; this is half the value chosen by Greenwood et al. (1995). We depart here from their assumption that the household capital is equal to the entire stock of durables plus residential structures to capture the idea that part of this stock is not used for household production, but rather is used solely for leisure (this assumption does not affect significantly our results). The share of market investment is constrained to equal $11.8 \%$ of market output, and the share of household investment is set equal to $6.75 \%$ of market output. Labor's share in the market sector is 0.69 , and is 0.80 in the household sector. The elasticity of substitution between capital and labor in each sector is 1 . The adjustment cost function is parameterized so that no adjustment costs are incurred in maintaining the steady state capital stock (i.e., in the steady state Tobin's q is one). The elasticity of the investment-to-capital ratio with respect to movements in Tobin's 
$\mathrm{q}$ is set at $\kappa=13.3$ as in Marianne Baxter and Mario J. Crucini $(1993,1995) .{ }^{5}$ The depreciation rates on the two capital stocks are $\delta_{M}=2.55$ percent per quarter in the market sector, and $\delta_{H}=2.30$ percent per quarter in the household sector.

\section{Productivity}

The quarterly trend rate of growth of labor-augmenting technical change is set at $\gamma=1.004$. The stochastic components of productivity, $A_{M t}$ and $A_{H t}$, are governed by the following vector $\mathrm{AR}(1)$ process:

$$
\left[\begin{array}{l}
\log A_{M, t+1} \\
\log A_{H, t+1}
\end{array}\right]=\left[\begin{array}{ll}
\rho_{1} & \nu_{1} \\
\nu_{1} & \rho_{1}
\end{array}\right]\left[\begin{array}{l}
\log A_{M t} \\
\log A_{H t}
\end{array}\right]+\left[\begin{array}{ll}
\rho_{2} & \nu_{2} \\
\nu_{2} & \rho_{2}
\end{array}\right]\left[\begin{array}{l}
\log A_{M, t-1} \\
\log A_{H, t-1}
\end{array}\right]+\left[\begin{array}{c}
\epsilon_{M, t+1} \\
\epsilon_{H, t+1}
\end{array}\right]
$$

with the correlation of innovations set at 0.67 in accordance with the parameterization of Greenwood et al. (1995).

We study three stochastic processes for the productivity shock. In the first case, we assume that technology follows a trend-stationary process with $\rho_{1}=0.90$, $\rho_{2}=0$. In the second case, we assume that technology is an $\operatorname{AR}(1)$ in first differences: we set $\rho_{1}=1.25, \rho_{2}=-0.25$. In both cases we assume that there is no transmission of shocks from one sector to the other: $\nu_{1}=\nu_{2}=0$. In the third and final case we assume that productivity is trend stationary, but that 
innovations in productivity spill over to the other sector with a one-quarter lag. This specification captures the idea that innovations that initially apply to one sector (such as microcomputers used in the market sector) eventually find uses in the home sector (microcomputers can be used at home to prepare one's own tax return). Specifically, we set $\rho_{1}=0.81, \nu_{1}=0.10, \rho_{2}=\nu_{2}=0$. In each case, we assume that the standard deviation of innovations to productivity shocks in both sectors is 0.0075, following Greenwood et al. (1995).

\section{Government}

The government has an essentially passive role-the reason for including a government sector is that taxation of capital is important for the level of the capital stock, investment shares, and the capital share in the market sector. The tax rate on market capital, $\tau_{K}$, is set at 0.70 , which is in the range estimated by several authors: see, for example, Martin Feldstein et al. (1983). The tax rate on market labor is set at $\tau_{N}=0.25$, which is in line with current effective tax rates, as reported by McGrattan et al. (1997). The model's results regarding excess sensitivity are largely insensitive to variations in these tax rates, even over fairly wide ranges. Government purchases are set at $G=0$, so that all tax proceeds are returned to individuals as lump-sum transfers. 


\section{Business-cycle implications}

Although this paper is not concerned with the business-cycle implications of the model per se, we present these for two reasons. First, for readers unfamiliar with the household production literature, we provide some evidence on the extent to which the household production model performs well in terms of replicating the salient features of business cycles. Second, these results show the extent to which our model of household production generates cycles that are similar to those generated by the earlier models.

Table 1 presents summary business-cycle statistics for postwar U.S. data and for our household production model. We present results for all three parametrization of the productivity shock process. Table 1 shows that our household production model fits the basic business-cycle statistics about well as the other household production models in the literature. In particular, the stationary models generally do a good job of replicating the pattern of relative volatility of market consumption (relative to market output), and produce relative volatility statistics for investment that are close to those in the data. The model underpredicts somewhat the volatility of labor input to the market sector, while the relative volatility of the wage rate is closer to that found in the data.

Although corresponding figures are not available from the data, it is interesting 
to see that the model predicts that household and market output are positively correlated although not strongly so, while household and market consumption are roughly uncorrelated. The model predicts that market consumption is highly correlated with market output, in fact, somewhat more so than found in the data. Overall, however, the model fits the stylized facts of household and market business cycles fairly well.

\section{The excess-sensitivity regression}

Following an idea of Hall (1978), Campbell and Mankiw (1989) propose a model in which there are two types of consumers: permanent income consumers, and "rule-of-thumb" consumers who simply consume their current income. Combining these two types of consumers leads to the following specification for consumption growth, $\Delta c_{t}$, as a function of income growth, $E_{t-1} \Delta y_{t}$, and the ex-ante real interest rate $r_{t-1, t}$ (which is known at time $t-1$ ), and an error term $u_{t}$ that captures the part of consumption growth that is unpredictable given past values of income growth and the interest rate, and other sources of error such as measurement error:

$$
\Delta c_{t}=\mu+\lambda E_{t-1} \Delta y_{t}+\theta r_{t-1, t}+u_{t}
$$


Campbell and Mankiw argue that $\lambda$ in equation (0.22) measures the fraction of the population that follows a rule of thumb; their instrumental-variables estimates of $\lambda$ range from 0.29 to 0.66 , depending on the instrument list and whether the interest rate is included in the regression. Their estimates of $\theta$ are typically very small, ranging from 0.02 to 0.15 , which they also view as inconsistent with the PIH since, in their specification, $\theta=1 / \sigma$ is the elasticity of intertemporal substitution and should thus be somewhat larger.

Campbell and Mankiw's regression is, of course, mis-specified in our model economy. That is: the error term $u_{t}$ includes other variables (notably, household sector variables) that affect the growth rate of market consumption. Most importantly, these omitted variables are correlated with expected income growth and the real interest rate. But it is still of interest to know what coefficient estimates an empirical researcher would find in our economy using the Campbell-Mankiw approach. This section shows that the empirical finding of excess sensitivity could result from individuals' substitutions between home and market work and between home and market consumption goods as relative prices and wages rates change. To show how excess sensitivity arises in our model, we begin by assuming that the model is true and that the researcher has an infinitely-long time series on all the variables in the model. Next, we show how the model implications for 
excess sensitivity change when the researcher continues to have an infinitely-long sample but has observations on only the conventional variables typically used as instruments. Finally, we suppose that the researcher is constrained by a finite sample (of approximately post-war length) and has access to data on the conventional instruments. In all cases, we find that data generated by the household production model would generate apparent "excess sensitivity" of the magnitude commonly found in the empirical literature.

\section{A. Large sample, full information results}

In this first example, we take as given that the household production model is correct, and explore the implications of this model for the coefficients $\lambda$ and $\theta$ when we suppose that the researcher has an infinitely long sample period and a dataset that includes all the variables in our model (the details of the computations are given in the Appendix). In the context of our quantitative equilibrium model, we can use the model solution to compute the exact conditional expectations of income growth and the ex-ante interest rate-we do not need to simulate the model. Given the conditional expectations and covariances, we can then compute the regression coefficients in eq. (0.22). Our interpretation of these estimates is that these are the large sample full-information coefficients of $\lambda$ and $\theta$ implied 
by our model. Table 2 presents results for benchmark model together with an extensive sensitivity analysis.

We begin with the benchmark parameterization. For the trend-stationary model without transmission of shocks across sectors, this approach yields $\lambda=$ $0.32, \theta=-0.03$. For the difference-stationary case, we obtain $\lambda=0.36, \theta=$ 0.08. The model with transmission of shocks across sectors produces $\lambda=0.69$, $\theta=-0.43$. Thus the benchmark model of household production model predicts that a researcher running the typical consumption growth regression should find apparent excess sensitivity in the form of a positive coefficient on expected output growth.

The positive coefficient on expected output growth derives from the intersectoral movement of labor in response to expected productivity differentials. Further, the model predicts a coefficient on the interest rate that is close to zero, especially in the absence of transmission of shocks across sectors, which is in line with the Campbell-Mankiw results. However, as shown in the simpler model of section II (see equation (0.13)) the coefficient on the interest rate is not, in general, equal to $1 / \sigma$, which would be 0.50 under our parameterization. Thus a small value of $\theta$ cannot be interpreted as evidence that consumers are insensitive to variations in the interest rate. 
The sensitivity analysis in Table 2 shows how these results vary with changes in the parameterization of the model. We begin by exploring the implications of altering the elasticity of substitution between home and market consumption goods. Our explanation for apparent excess sensitivity hinges on substitutions between different goods, so it is important to explore the effects of changing these elasticities. Experiments 1 and 2 show the effects of a reduced elasticity of substitution between home and market goods; experiment 3 increases the elasticity of substitution to the high end of its plausible range. Even with zero elasticity (experiment 1) there is still apparent excess sensitivity, with $\lambda$ ranging from 0.11 to 0.17 . The reason that apparent excess sensitivity arises in this case is that the consumer still undertakes substitutions between leisure and the consumption aggregate. Put differently, the aggregate supply of labor (to home and market sectors together) responds to variations in the real wage. A high elasticity of substitution leads to increases in $\lambda$, as expected.

Experiment 4 presents results for a case in which the aggregate labor supply is fixed (leisure is constant or, equivalently, individuals do not value leisure). Apparent excess sensitivity arises in this case as well, with values of $\lambda$ ranging from 0.40 to 0.75 . In this case, apparent excess sensitivity stems from the fact that the consumer substitutes between consumption of the home and market good, 
even though aggregate labor supply is fixed. Evidently, then, apparent excess sensitivity will only disappear if market consumption enters the utility function separably from home production and leisure. Based on the existing empirical evidence, we view this specification as implausible.

Experiments 5 and 6 show that variations in risk aversion have little effect on the excess sensitivity result. Experiment 7 reduces the correlation of the shocks to the home and market sectors, which tends to increase apparent excess sensitivity by increasing the scope for substitutions across sectors (there is less tendency for marginal products in the two sectors to move together). Experiments 8 and 9 illustrate the effect of changing the assumed elasticity of adjustment costs for capital. Abolishing adjustment costs has little effect on apparent excess sensitivity, while increasing adjustment costs leads to much higher apparent excess sensitivity. Finally, experiment 10 shows that apparent excess sensitivity will arise even if there are no productivity shocks to the household sector-shocks to the market sector alone are sufficient. Overall, we find that the predictions for the coefficient on income growth $(\lambda)$ are remarkably robust, whereas $\theta$ is found to be more sensitive to departures from the baseline model. 


\section{B. Large sample, limited information estimates}

The preceding sub-section showed that the household production model can explain apparent excess sensitivity, based on the population, or large sample, moments implied by the baseline parameterizations of the model. However, empirical research is constrained by the fact that some variables that are important for constructing conditional covariances (i.e., some useful instruments) are not available to the researcher. This sub-section follows standard empirical practice in using lagged values of consumption, output, and the interest rate as instruments (see the Appendix for details). That is: we use our model to construct 'instrumented' versions of $\Delta y_{t}$ and $r_{t-1, t}$ as linear projections on lagged endogenous variables. ${ }^{6}$ Following Campbell and Mankiw (1989), we choose the following as our basic instrument set: $\triangle c_{t-1}, \triangle c_{t-2}, \triangle c_{t-3}, r_{t-2, t-1}, r_{t-3, t-2}, r_{t-4, t-3}$. In the context of the model, it is not necessary to instrument $r_{t-1, t}$ because this is a risk-free rate (it is unrelated to the period $t$ error since it is known at time $t-1$ ). However, we instrument this variable since this procedure is typically followed in the empirical literature. $^{7}$

Table 3 gives the results for the procedures that use lagged observable endogenous variables as instruments. With this procedure, there is no sampling uncertainty and no small-sample bias. Table 3 shows that, in the stationary case 
without transmission of cross sectors, the estimates are $\lambda=0.05, \theta=0.42$. In the nonstationary case without transmission, the estimates are $\lambda=0.30, \theta=0.43$. (The corresponding coefficients from Table 2 are presented for comparison.) These coefficient estimates differ from those computed using exact conditional expectations because the linear projections yield an imperfect measure of the exact conditional expectations which were used in Table 2 . With transmission of shocks across sectors (panel C), the full information procedure yields $\lambda=0.69, \theta=-0.43$; while the limited information procedure yields $\lambda=0.44$ and $\theta=0.06$.

\section{Finite sample, limited information results}

To explore the small-sample properties of the procedure which uses a restricted set of variables as instruments, we followed a Monte-Carlo approach. Specifically, we simulated our model to generate time series of length 130 quarters $(32.5$ years-approximately the length of time studied by prior researchers). Using the simulated data, we computed the instrumental variables estimates of $\lambda$ and $\theta$ using the instrument list specified earlier. We performed 1000 such simulations; the mean estimates of the coefficients are reported in Table 3, together with the standard deviation of the coefficient estimates across the 1000 simulations. This table also reports sample means of the partial $R^{2}$ statistics from the first-stage 
regressions, which Shea (1996) recommends as the correct measure of instrument relevance in multivariate settings.

For the stationary case without transmission of shocks across sectors (Panel A) the mean values of the coefficients are $\lambda=0.53, \theta=-0.75$, while the population values for the model-based variables approach were $\lambda=0.05, \theta=0.42$. Over 1000 trials, the standard deviation of the coefficient on output $(\lambda)$ was 0.15 . The considerable difference between the computed and the simulated coefficient values is linked to the weak predictability of the regressors and of consumption growth itself. This can be seen in the low values of the $R^{2}$ and partial $R^{2}$ statistics for the regressions of consumption, output and the interest rate on the instruments. ${ }^{8}$ In the nonstationary model without transmission (Panel B) we find similar results. The average value of the coefficients from the simulated, shorter sample differ markedly from both the population values for the model-based variables approach and the coefficients yielded by the exact conditional expectations. There continue to be low partial $R^{2}$ statistics for the instrumented variables.

Looking at the model with transmission of shocks across sectors, we find that the three groups of coefficients differ less than in the prior two cases due to improved predictability of consumption with this shock process.

Campbell and Mankiw also report regressions of consumption growth on out- 
put growth without the interest rate:

$$
\Delta c_{t}=\mu+\lambda \Delta y_{t}+\varepsilon_{t}
$$

We explored estimation of eq. (0.23) as a check on the robustness of our estimates of $\lambda$; these results are not reported in the paper. In each case, we found that the values for $\lambda$ obtained from this equation to those obtained when the interest rate is included. ${ }^{9}$

\section{Implications for testing the PIH}

Our results have implications for empirical testing of the PIH. ${ }^{10}$ In particular, we have shown that it is inappropriate to test the PIH by looking at the correlation between market consumption and income growth due to an increase in market wages. However, tests that involve income growth due to windfalls or changes in the timing of predictable income receipts should still be valid tests of the PIH. Tests of this latter sort have been carried out using micro data by Matthew D. Shapiro and Joel Slemrod (1995) who surveyed consumers to determine effects of the 1992 change in income tax withholding procedures. Nicholas Souleles (1996) studies the relationship between consumption and the receipt of income tax re- 
funds. These studies find some evidence of excess sensitivity and thus present an ongoing challenge to the PIH.

In the context of our model, a decrease in government purchases acts as a windfall increase in consumer disposable income that is unrelated to wages. We used our model to study an unexpected, purely temporary decrease in government purchases. ${ }^{11}$ The excess sensitivity coefficient is $\lambda=-0.0175$ for this type of shock (using the model's exact conditional expectation). The intuition behind the finding of a slight negative dependence of consumption growth on windfall growth in disposable market income is as follows. The decrease in government purchases increases households' wealth. Leisure rises, as does consumption of the home good. Consumption of the market good increases, while labor input to the market sector falls. Thus, we have a natural mechanism leading to a negative correlation between labor income and market consumption. This suggests that an alternative approach to testing the $\mathrm{PIH}$ would be to determine the effect on consumption of changes in government spending on goods and services that do not affect individual utility (or affect it only additively) and which do not affect labor productivity. 


\section{Summary and conclusions}

This paper has shown that a macro model with household production can rationalize the observed "excess sensitivity" of consumption growth to predictable output growth. Our story is based on the idea that consumers substitute between home goods and market goods according to their relative price, and substitute between work at home and work in the market depending on the relative wage. That consumers and workers do undertake these substitutions has been documented by Benhabib et al. (1990) Victor Rios-Rull (1990), and F. Thomas Juster

and Frank P. Stafford (1991). Our paper shows that plausible substitutions along these lines can produce exactly the empirical finding that predictable growth in market output is correlated with consumption growth. We began by demonstrating this result within a simple, partial equilibrium model of consumer choice, and then showed that the result continues to hold within a general equilibrium model with neoclassical investment dynamics. We explored the implications of the quantitative equilibrium model for the empirical estimates that would be obtained by researchers running the "excess sensitivity regressions" on data generated by our model. We found that these researchers would find a positive coefficient on output growth in this regression, which should not be interpreted as excess sensitivity or 
as a violation of the PIH. Further, we found that the coefficient on the interest rate is predicted to differ substantially from the inverse of the coefficient of relative risk aversion, and that this coefficient estimate is particularly sensitive to choice of instruments and to small sample bias.

Our story has stressed substitutions of labor effort across sectors depending on the relative wage rate. It is natural to wonder how things would work if hours of market work were unrelated to wages or productivity, as in Richard Rogerson's (1988) "lottery model," or if there were "involuntary unemployment." Apparent excess sensitivity would still arise in these settings, for the following reason. Following dismissal from the work force, an individual would have less market income and more time to allocate to leisure and to household production. Less market income leads to lower consumption of the market good, while the increase in the time available for non-market activities would lead to increases in the consumption of the home good and leisure. Qualitatively, these are the same effects stressed in our equilibrium model. The only difference is that we would not expect the value marginal product of labor to be equalized across home and market sectors in these alternative settings.

Finally, empirical results obtained in a recent paper by Attanasio and Browning (1995) can be interpreted as lending support to the household production 
story. Attanasio and Browning study micro data on consumption and find that excess sensitivity of consumption to current income disappears once one controls for variables such as the individual's age, number of children, whether one or both spouses work, and the amount of labor supplied to the market. These variables all seem likely to be good proxies for the relative costs and benefits to working in the market sector and consuming market goods versus working in the home sector and consuming home-produced goods.

Overall, our results suggest that it would be premature to abandon the PIH as a central component of modern macroeconomic models. However, these results also strengthen the case that understanding substitutions between the household and market sectors are likely to be central to understanding the behavior of consumption over the business cycle. 


\section{References}

Attanasio, Orazio P. and Martin Browning. "Consumption over the Life Cycle and over the Business Cycle." American Economic Review, December $1995, \underline{85}(5)$, pp. 1118-37.

Baxter, Marianne. "Are Consumer Durables Important for Business Cycles?."

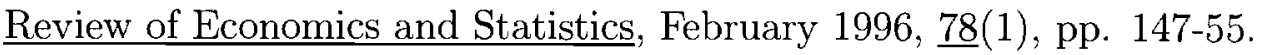

Baxter, Marianne and Crucini, Mario J. "Explaining Saving-Investment Correlations." American Economic Review, June 1993, 3⑶, pp. 416-436. . "Business Cycles and the Asset Structure of Foreign Trade." International Economic Review, November 1995, 36(4), pp. 821-54.

Becker, Gary S. "A Theory of the Allocation of Time," Economic Journal, September 1965, $\underline{75}$, pp. 493-517.

Benhabib, Jess; Rogerson, Richard and Wright, Randall. "Homework in Macroeconomics: Household Production and Aggregate Fluctuations." Journal of Political Economy, December, 1991, $\underline{99}(6)$, pp. 1166-1187. 
Caballero Ricardo J. "Consumption Puzzles and Precautionary Savings." Journal of Monetary Economics, January 1990, 25(1), pp. 113-136.

Campbell, John Y. and Ludvigson, Sydney. "Elasticities of Substitution in Real Business Cycle Models with Home Production." Working paper, Harvard University, 1997.

Campbell John Y. and Mankiw, N. Gregory. "Consumption, Income, and Interest Rates: Reinterpreting the Time Series Evidence." NBER Macroeconomics Annual, 1989, pp. 185-216.

Campbell John Y. and Mankiw, N. Gregory. "Permanent Income, Current Income, and Consumption." Journal of Business and Economic Statistics, July $1990, \underline{8}(3)$, pp. $265-279$.

Campbell John Y. and Mankiw, N. Gregory. "The Response of Consumption to Income: A Cross-Country Investigation." European Economic Review, May 1991, 35(4), pp. 723-767.

Canova, Fabio and Ubide, Angel. "International Business Cycles, Financial Markets and Household Production." Universitat Pompeu Fabra (Barcelona, Spain) Discussion Paper Series 27, Working paper \#204, Jan- 
uary 1997, and forthcoming, Journal of Economic Dynamics and Control.

Christiano, Lawrence; Eichenbaum, Martin, and Marshall, David. "The Permanent Income Hypothesis Revisited." Econometrica, March 1991, 59(2), pp. 397-424.

Cochrane, John H. "Comment: 'The Response of Consumption to Income: A Cross-Country Investigation' by J.Y. Campbell and N.G. Mankiw, 'Why Test the Permanent Income Hypothesis?' " European Economic Review, May 1990, $\underline{35}(4)$, pp. 757-764.

Eichenbaum, Martin and Hansen, Lars Peter. "Estimating Models with Intertemporal Substitution Using Aggregate Time Series Data". Journal of Business and Economic Statistics, January 1990, $\underline{8}(1)$, pp. 53-69.

Feldstein, Martin S., Dicks-Mireaux, Louis and Poterba, James. "The Effective Tax Rate and the Pretax Rate of Return." Journal of Public Economics, July 1983, 21(2), pp. 129-158.

Flavin, Marjorie A. "The Adjustment of Consumption to Changing Expectations About Future Income." Journal of Political Economy, October 1981, 89(5), pp.974-1009. 
Friedman, Milton. A Theory of the Consumption Function. Princeton, New Jersey: Princeton University Press, 1957.

Garber, Peter and King, Robert. "Deep Structural Excavation? A Critique of Euler Equation Methods." University of Rochester Discussion Paper No. 83-14, 1983.

Greenwood, Jeremy, and Hercowitz, Zvi."The Allocation of Capital and Time over the Business Cycle." Journal of Political Economy, December 1991, $\underline{99}(6)$, pp. 1188-1214.

Greenwood, Jeremy; Rogerson, Richard and Wright Randall. "Household Production in Real Business cycle theory," in: T. Cooley, ed., Frontiers of Business Cycle Research. Princeton: Princeton University Press, 1995, pp. $157-174$.

Hall Robert E. "Stochastic Implications of the Life Cycle-Permanent Income Hypothesis: Theory and Evidence." Journal of Political Economy, December $1978,86(6)$, pp. $971-987$.

Juster, F. Thomas and Stafford, Frank P. "The Allocation of Time: Empirical Findings, Behavioral Models, and Problems of Measurement." Journal 
of Economic Literature, June 1991, 29 (2), pp. 471-522.

King, Robert G., Plosser, Charles and Rebelo, Sergio. "Production, Growth and Business Cycles: Technical Appendix." Working paper, Rochester Center for Economic Research, 1987.

Mankiw Gregory N. "Consumer Durables and the Real Interest Rate." Review of Economics and Statistics, August 1985, $\underline{67}$ (3), pp. 353-362.

McGrattan, Ellen; Rogerson, Richard and Wright, Randall. "An Equilibrium Model of the Business Cycle with Household Production and Fiscal Policy." International Economic Review, May 1997, 38(2), pp. 267-290.

Rios-Rull, Victor. "Working in the Market, Home Production, and the Acquisition of Skills: A General-Equilibrium Approach." ㅆmerican Economic $\underline{\text { Review, }}$, September 1993, $\underline{83}(4)$, pp. 893-907.

Rogerson, Richard. "Indivisible Labor, Lotteries and Equilibrium." Journal

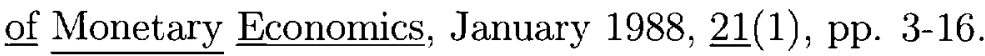

Rupert, Peter; Rogerson, Richard, and Wright Randall. "Estimating Substitution Elasticities in Household Production Models." Economic Theory, June $1995, \underline{6}(1)$, pp. 179-193. 
Shapiro, Matthew D. and Joel Slemrod. "Consumer Response to the Timing of Income: Evidence from a Change in Tax Withholding." American Economic Review, March 1995, 85(1), pp. 274-283.

Shea, John. "Instrument Relevance in Multivariate Linear Models: A simple Measure." Review of Economics and Statistics, May 1997, 79(2), pp. 34852.

Souleles, Nicholas. "The Response of Household Consumption to Income Tax Refunds." Working paper, Wharton School of Business, 1996, and forthcoming, American Economic Review. 


\section{Endnotes}

1. See, for example, the contributions of Benhabib, Rogerson, and Wright (1991), Jeremy Greenwood and Zvi Hercowitz (1991), Greenwood et al. (1995), McGrattan et al. (1996), Fabio Canova and Angel Ubide (1997), and John Y. Campbell and Sydney Ludvigson (1997).

2. This is an example of the type of problem discussed by Peter Garber and Robert G. King (1983). It is also possible to generate apparent excess sensitivity through substitutions on the consumption/leisure margin, as in Orazio P. Attanasio and Martin Browning (1995). We focus on alternative ways of generating consumption goods through substitution between home and market-generated consumption, while incorporating standard labor/leisure choice.

3. In fact, the coefficient on expected output growth will be positive even if $\gamma_{1}$ is negative, so long as $1+\gamma_{1}$ is positive.

4. Anyone who has found himself eating pizza for the fifth night in a row when trying to meet a deadline will understand the basic idea here.

5. Adjustment costs are incorporated into our model, in contrast to the model of Greenwood et al., because they substantially improve the investment behavior of the model. The importance of adjustment costs for the dynamics of investment 
in multi-sector environments is discussed in Baxter and Crucini $(1993,1995)$ and Baxter (1996).

6. One of the puzzles uncovered by Campbell and Mankiw is that the correlation between consumption and predictable income is higher than the correlation between consumption and raw income. As a result, the OLS estimate of $\lambda$, which should in theory be upward biased due to a positive correlation between income innovations and optimal consumption, turns out to be lower than the IV estimate of $\lambda$ empirically. This is not the case for our model, as reconciling these results seems to require measurement error in aggregate income. Our model abstracts from measurement error.

7. An alternative strategy would be to take an ex-ante uncertain return, such as the return on capital, so that the IV procedure would actually be necessary. We experimented with this alternative approach, but it did not lead to significantly different results. We also experimented with alternative instrument sets. For example, we used the following instrument set: $\triangle y_{t-1}, \triangle y_{t-2}, \triangle y_{t-3}, r_{t-2, t-1}, r_{t-3, t-2}, r_{t-4, t-3}$. The results did not change appreciably. Also, many researchers use twice-lagged instruments to avoid potential problems due to time-averaged consumption data; for the results reported here we lag the instruments only once. Exploration with time-averaged model-generated data and twice lagged instruments did not yield 
different results.

8. As a check on our Monte Carlo procedure, we performed 30 simulations of length 3000 (750 years) for the stationary model without transmission. The mean coefficient values that we obtain are $\lambda=0.15, \theta=0.29$. These are much closer to the large sample, full information coefficients of $\lambda=0.05, \theta=0.42$. Thus with sufficiently long samples, the procedure converges to the large sample, limited information estimates. A discussion of this econometric issue can be found in Nelson (1990).

9. An alternative choice for the instruments, $\Delta y_{t-1}, \Delta y_{t-2}, \Delta y_{t-3}$, leads to similar conclusions.

10. We are grateful to a referee for pointing out these implications to us and for suggesting the experiment involving changes in government spending.

11. We specified that shocks to government purchases were i.i.d., and then studied the response to a decrease in purchases. The steady state share of government purchases was set at $20 \%$ of total output. Results were similar for persistent but ultimately temporary shocks to government purchases. 


\section{Appendix}

This appendix explains the methods used to compute the results in Section IV. The solution to our model can be written as follows. First, the state variables of the problem evolve according to:

$$
s_{t}=M s_{t-1}+G \epsilon_{t}
$$

where $s_{t}$ is an $s \times 1$ vector of state variables, $\epsilon_{t}$ is a $k \times 1$ vector of shocks, and $M$ and $G$ are coefficient matrices. The solution to the model is given by (0.24) together with eq. (0.24) which describe how other variables of interestconsumption, output, the interest rate, labor input, etc.-depend on the state vector:

$$
W_{t}=\Pi s_{t}
$$

where $W_{t}$ is a $w \times 1$ vector and $\Pi$ is a $w \times s$ coefficient matrix.

We use this system to generate the results that a researcher would find if he were studying data produced by our model economy. Some of the results are obtained under the assumption that the researcher has an infinite amount of data on all variables in the model. These results are termed "large-sample, 
full-information" results. Other results assume an infinite amount of data but on a limited set of variables. These results are termed "large-sample, limitedinformation" results. Finally, we explore Monte-Carlo results based on a sample length of 130 quarters (approximately the sample length used by prior researchers) using a limited set of variables. These are called "finite-sample, limitedinformation" results.

The Campbell-Mankiw equation is given below:

$$
\Delta c_{t}=\mu+\lambda E_{t-1} \Delta y_{t}+\theta E_{t-1} r_{t-1, t}+u_{t}
$$

Since the expectations in (0.24) are not observable, Campbell and Mankiw specify their estimating equation as follows:

$$
\Delta c_{t}=\mu+\lambda \Delta y_{t}+\theta r_{t-1, t}+\varepsilon_{t}
$$

and then use instrumental-variables procedures to try to correct for the simultaneity bias that arises because the expectation errors in $\Delta y_{t}$ and $r_{t-1, t}$ are correlated with $\varepsilon_{t}$.

As discussed in the text, this equation is mis-specified in the model, since 
the growth rate of market consumption depends on more variables than income growth and the interest rate. Specifically, there are omitted variables in this regression that are included in the "error term" $\varepsilon_{t}$. These omitted variables will influence the results that would be obtained by a researcher estimating $(0.24)$ using data generated by the household production model.

\section{A-1. Large sample, full information results}

To produce our "large sample, full information" results, we proceed as follows. First, we work directly with the specification (0.24) since we can use our model to compute the necessary expectations. Specifically, from $(0.24)$ and $(0.24)$, we have

$$
\begin{gathered}
E_{t-1} W_{t}=\Pi E_{t-1} s_{t} \\
=\Pi M s_{t-1} \\
=\digamma s_{t-1} .
\end{gathered}
$$

Estimates of the coefficients $\lambda$ and $\theta$ are found by solving the least-squares 
'normal equations':

$$
\begin{gathered}
\frac{1}{T} \sum_{t=0}^{T}\left(E_{t-1} \Delta c_{t}-\lambda E_{t-1} \Delta y_{t}-\theta E_{t-1} r_{t-1, t}\right) E_{t-1} \Delta y_{t}=0 \\
\frac{1}{T} \sum_{t=0}^{T}\left(E_{t-1} \Delta c_{t}-\lambda E_{t-1} \Delta y_{t}-\theta E_{t-1} r_{t-1, t}\right) E_{t-1} \Delta r_{t-1, t}=0 .
\end{gathered}
$$

In the context of our model economy, we use equation (0.24) to construct the expectations in $(0.24)$ and $(0.24)$, where the notation $F_{j}$ denotes the row of the matrix $F$ associated with variable, yielding:

$$
\begin{aligned}
& \frac{1}{T} \sum_{t=0}^{T}\left(\digamma_{c} s_{t-1}-\lambda \digamma_{y} s_{t-1}-\theta \digamma_{r} s_{t-1}\right) \digamma_{y} s_{t-1}=0 \\
& \frac{1}{T} \sum_{t=0}^{T}\left(\digamma_{c} s_{t-1}-\lambda \digamma_{y} s_{t-1}-\theta \digamma_{r} s_{t-1}\right) \digamma_{r} s_{t-1}=0 .
\end{aligned}
$$

For the "full-information" results, we take the probability limits of (0.24) and (0.24) as $T \rightarrow \infty$ to obtain:

$$
\begin{aligned}
& \sigma_{c y}-\lambda \sigma_{y y}-\theta \sigma_{y r}=0 \\
& \sigma_{c r}-\lambda \sigma_{y r}-\theta \sigma_{r r}=0
\end{aligned}
$$


where $\sigma_{i j}$ denotes the population, or large-sample covariance of variable $i$ with variable $j$. Given these covariances, these 2 equations can be solved for the two unknowns, $\lambda$ and $\theta$.

It is easiest to see how the moments in $(0.24)$ and $(0.24)$ can be calculated if we assume that the system is stationary. Let $\Xi$ denote the probability limit of the variance-covariance matrix of $s_{t-1}$. This variance-covariance matrix can be computed in a variety of ways for example, by solving the matrix equation $\Xi=$ $M \Xi M^{\prime}+E\left(\varepsilon \varepsilon^{\prime}\right)$. We then obtain the following versions of the normal equations:

$$
\begin{aligned}
& \digamma_{c} \Xi \digamma_{y}^{\prime}-\lambda \digamma_{y} \Xi \digamma_{y}^{\prime}-\theta \digamma_{r} \Xi \digamma_{y}^{\prime}=0 \\
& \digamma_{c} \Xi \digamma_{r}^{\prime}-\lambda \digamma_{y} \Xi \digamma_{r}^{\prime}-\theta \digamma_{r} \Xi \digamma_{r}^{\prime}=0 .
\end{aligned}
$$

These two equations are then solved for the two unknown coefficients, $\lambda$ and $\theta$, as reported in Table 2 . When the shocks to the state variables are nonstationary $\Xi$ does not exist. Note, however, that even in the nonstationary case the covariances in (0.24) and (0.24) are still well-defined, as they involve growth rates of consumption and income as well as the level of the real interest rate, all of which are stationary. 


\section{A-2. Large sample, limited information results}

In applied econometric contexts, the researcher typically does not have enough information compute the necessary expectations: in our context, these would be $E_{t-1} \Delta y_{t}$ and $E_{t-1} r_{t-1, t}$. Thus researchers like Campbell and Mankiw use an instrumental variables procedure which we find convenient to discuss as two-stageleast-squares. Under this procedure, the variables $\Delta y_{t}$ and $r_{t-1, t}$ are regressed on instruments, where valid instruments are any variables correlated with $\Delta y_{t}$ and $r_{t-1, t}$ but are uncorrelated with $\varepsilon_{t}$ in $(0.24)$ and with the expectation errors $\left(\Delta y_{t}-E_{t-1} \Delta y_{t}\right)$ and $\left(r_{t-1, t}-E_{t-1} r_{t-1, t}\right)$

We let $X_{t}$ denote the $n \times 1$ vector of date $t$ observations on the instruments. For compactness, we rewrite $(0.24)$ as

$$
\Delta c_{t}=\beta^{\prime} Z_{t}
$$

where $Z_{t}=\left[1, \Delta y_{t}, r_{t-1, t}\right]^{\prime}$ and $\beta=[\mu \lambda \theta]^{\prime}$. The 'first-stage' regression involves running an OLS regression of $Z_{t}$ on $X_{t}$ :

$$
Z_{t}=\delta^{\prime} X_{t}+e_{t}
$$


The 'second-stage' regression involves replacing $Z_{t}$ in eq. $(0.24)$ with the fitted values, $\hat{Z}_{t}=\hat{\delta}^{\prime} X_{t}$, from eq. (0.24). Then the two-stage-least-squares estimator of $\beta$ is given by:

$$
\hat{\beta}_{2 S L S}=\left[\sum_{t=0}^{T} \hat{Z}_{t}^{\prime} \hat{Z}_{t}\right]^{-1}\left[\sum_{t=0}^{T} \hat{Z}_{t}^{\prime} \Delta c_{t}\right]
$$

As $T \rightarrow \infty$ the estimator $\hat{\beta}_{2 S L S}$ converges in probability to $E\left(\hat{Z}_{t}^{\prime} \hat{Z}_{t}\right)^{-1} E\left(\hat{Z}_{t}^{\prime} \Delta c_{t}\right)$.

We used our model to compute a large sample version of $\hat{\beta}_{2 S L S}$ as follows. In the 'first stage' we computed $\hat{Z}_{t}$ by projecting $Z_{t}$ on the instruments $X_{t}$. The $X_{t}$ depend on the state vector as follows:

$$
X_{t}=\digamma_{X} s_{t-1}
$$

through a version of equation $(0.24)$, where $(0.24)$ reflects the fact that, in our application the instruments $X_{t}$ contain no date-t variables at all. Further, the state vector $s_{t-1}$ must be augmented to include additional lags of the state variables as necessary, depending on the instrument list employed. The 'first stage' projects $Z_{t}$ on $X_{t}$, yielding an estimate of $\delta$; the second stage computes $\hat{\beta}_{2 S L S}$ according to $(0.24)$. These estimates are reported in Table 3 . 


\section{A-3. Finite sample, limited information results}

To investigate the properties of estimates obtained by researchers constrained to using a finite amount of data, we employed a Monte Carlo procedure. Specifically, we generated 1000 simulations of our model, where each simulation was of length 130 quarters. For each simulation, we used the simulated data to construct an

estimate of $\hat{\beta}_{2 S L S}$ in exactly the same way as Campbell-Mankiw would have, had their data been generated by our model. The mean estimate of $\hat{\beta}_{2 S L S}$ over the 1000 simulations is reported in Table 3, together with the standard error of the estimate across the simulations. 


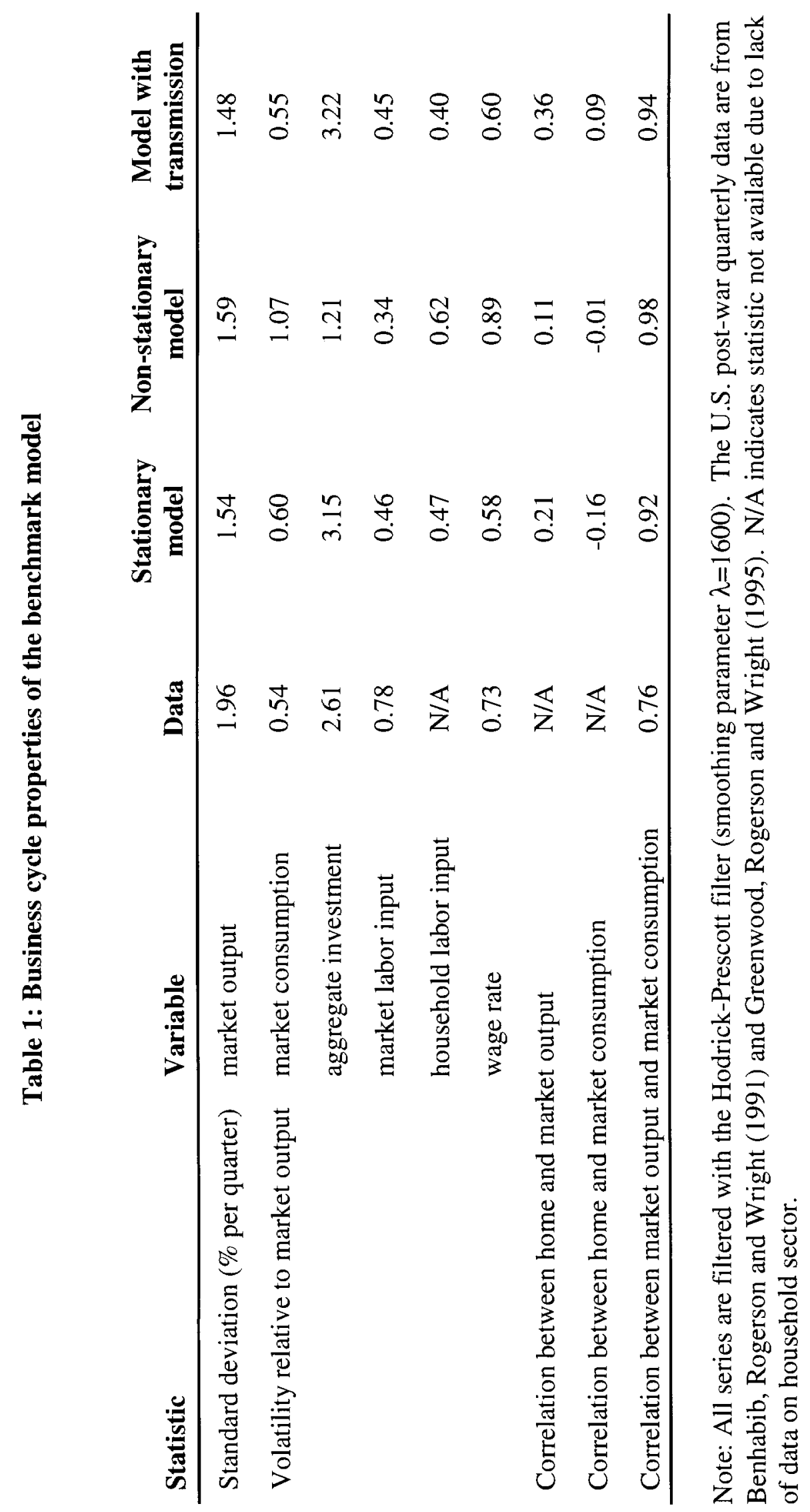




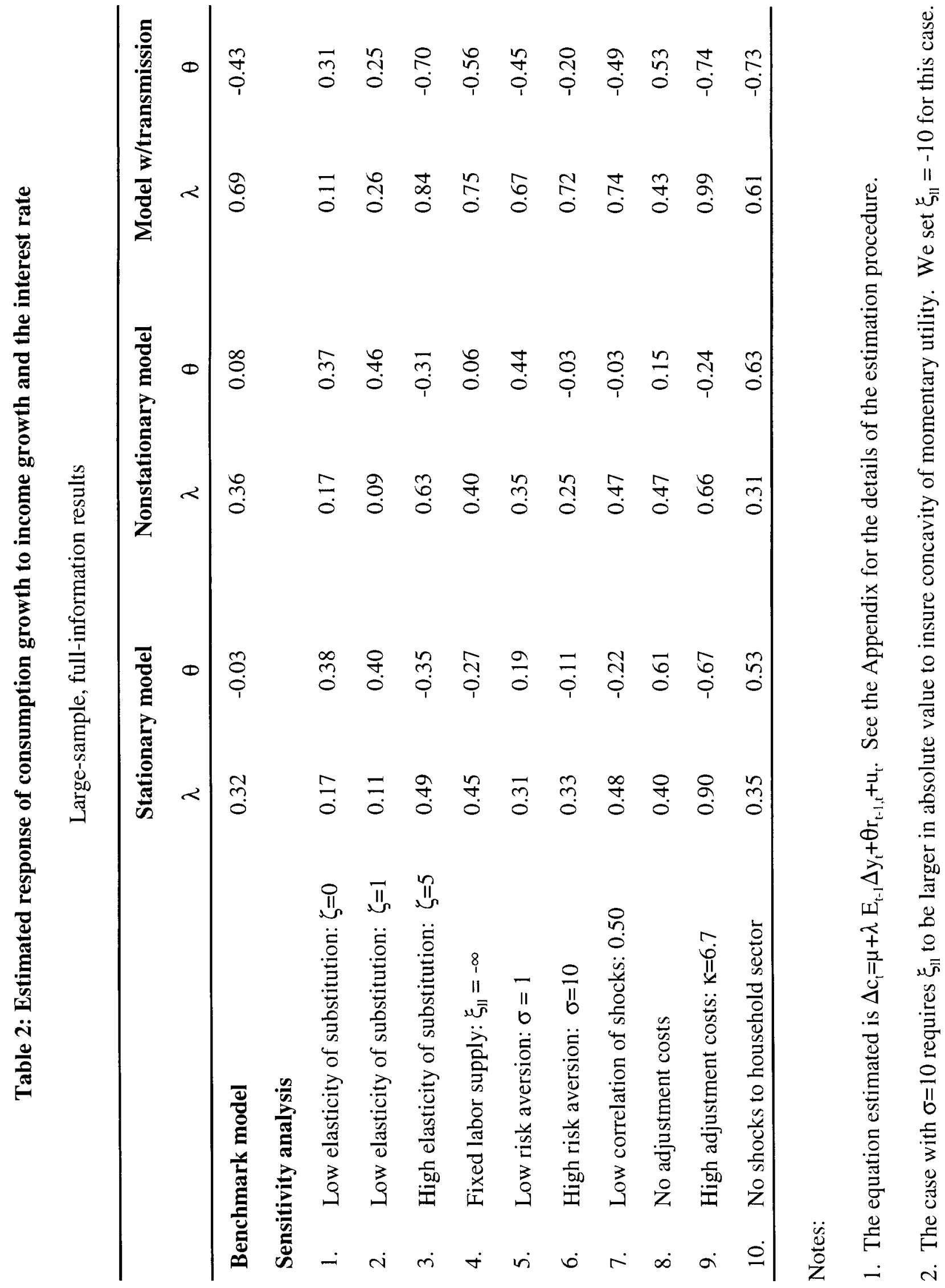


Table 3: Estimated response of consumption growth to income growth and the interest rate Comparison of three estimation methods

\begin{tabular}{cccc}
\hline & $\begin{array}{c}\text { Coefficient } \\
\text { estimates }\end{array}$ & & $\begin{array}{c}\text { Partial } \mathbf{R}^{2} \text { from } \\
\text { regression on } \\
\text { instruments }\end{array}$ \\
$\lambda$ & $\theta$ & y & $\mathbf{r}$ \\
\hline
\end{tabular}

\section{A. Stationary model without \\ transmission of shocks across sectors}

Large sample, full information

Large sample, partial information

Finite sample, partial information

$$
\text { (Standard error) }
$$

\section{B. Nonstationary model without transmission of shocks across sectors}

Large sample, full information

Large sample, partial information

Finite sample, partial information

$$
\text { (Standard error) }
$$

\section{Model with transmission of shocks across sectors}

Large sample, full information

Large sample, partial information

Finite sample, partial information

(Standard error)

$\begin{array}{ll}0.32 & -0.03 \\ 0.05 & 0.42\end{array}$

$\begin{array}{llll}0.53 & -0.75 & 0.04 & 0.46\end{array}$

$\begin{array}{lll}(0.15) & (0.91) \quad(0.02)\end{array}$

$\begin{array}{lrrr}0.36 & 0.08 & & \\ 0.30 & 0.43 & & \\ 0.81 & -1.07 & 0.09 & 0.44 \\ (0.24) & (0.66) & (0.04) & (0.14)\end{array}$

$\begin{array}{lrrr}0.36 & 0.08 & & \\ 0.30 & 0.43 & & \\ 0.81 & -1.07 & 0.09 & 0.44 \\ (0.24) & (0.66) & (0.04) & (0.14)\end{array}$

$0.69-0.43$

$0.44 \quad 0.06$

$0.52-0.14$

0.04

0.39

$(0.14) \quad(0.73) \quad(0.02)$

1. The equation estimated is $\Delta \mathrm{c}_{\mathrm{t}}=\mu+\lambda \mathrm{E}_{\mathrm{t}-1} \Delta \mathrm{y}_{\mathrm{t}}+\theta \mathrm{r}_{\mathrm{t}-\mathrm{t}, \mathrm{t}}+\mathrm{u}_{\mathrm{t}}$. For the large sample, full information results and the large sample, partial information results, we used the model solution to directly compute measures of the expectations in this equation. For the finite sample, partial information results, we simulated the model and employed standard two-stage-least-squares procedures on the following equation, which replaces expectations with realizations: $\Delta \mathrm{c}_{\mathrm{t}}=\mu+\lambda \Delta \mathrm{y}_{\mathrm{t}}+\theta \mathrm{r}_{\mathrm{t}-\mathrm{t}, \mathrm{t}}+\mathrm{u}_{\mathrm{t}}$. See the Appendix for the details of the estimation procedure.

2. In the finite sample, limited information case, the simulation results are obtained from 1000 runs with 130 usable data points; numbers in parentheses are standard errors of the coefficient estimates over the 1000 runs. Time required for 1000 runs on a Pentium Pro $200 \mathrm{Mhz}$ processor was approximately 5 minutes. Instruments for both limited information cases are $\Delta \mathrm{c}_{\mathrm{t}-1}, \Delta \mathrm{c}_{\mathrm{t}-2}, \Delta \mathrm{c}_{\mathrm{t}-3}, \mathrm{r}_{\mathrm{t}-2, \mathrm{t}-1}, \mathrm{r}_{\mathrm{t}-3, \mathrm{t}-\mathrm{-},}, \mathrm{r}_{\mathrm{t}-4, \mathrm{t}-\mathrm{-}-\mathrm{f}}$.

3. Partial $R^{2}$ statistics are described by Shea (1996). 